Article

\title{
Vibrational and Thermodynamic Properties of Hydrous Iron-Bearing Lowermost Mantle Minerals
}

\author{
Jiajun Jiang ${ }^{1,2}$, Joshua M. R. Muir ${ }^{2}$ and Feiwu Zhang ${ }^{2, *}$ (I) \\ 1 Faculty of Land Resources Engineering, Kunming University of Science and Technology, \\ Kunming 650093, China; jiangjiajun@kust.edu.cn \\ 2 State Key Laboratory of Ore Deposit Geochemistry, Institute of Geochemistry, Chinese Academy of Sciences, \\ Guiyang 550081, China; j.m.r.muir@mail.gyig.ac.cn \\ * Correspondence: zhangfeiwu@vip.gyig.ac.cn
}

Citation: Jiang, J.; Muir, J.M.R.;

Zhang, F. Vibrational and

Thermodynamic Properties of

Hydrous Iron-Bearing Lowermost Mantle Minerals. Minerals 2021, 11, 885. https://doi.org/10.3390/ $\min 11080885$

Academic Editors: Anna Pakhomova and Ilya Kupenko

Received: 29 June 2021

Accepted: 14 August 2021

Published: 16 August 2021

Publisher's Note: MDPI stays neutral with regard to jurisdictional claims in published maps and institutional affiliations.

Copyright: (c) 2021 by the authors. Licensee MDPI, Basel, Switzerland. This article is an open access article distributed under the terms and conditions of the Creative Commons Attribution (CC BY) license (https:// creativecommons.org/licenses/by/ $4.0 /)$.

\begin{abstract}
The vibrational and thermodynamic properties of minerals are key to understanding the phase stability and the thermal structure of the Earth's mantle. In this study, we modeled hydrous iron-bearing bridgmanite $(\mathrm{Brg})$ and post-perovskite $(\mathrm{PPv})$ with different $\left[\mathrm{Fe}^{3+}-\mathrm{H}\right]$ defect configurations using first-principles calculations combined with quasi-harmonic approximations (QHA). $\mathrm{Fe}^{3+}-\mathrm{H}$ configurations can be vibrationally stable in Brg and PPv; the site occupancy of this defect will strongly affect its thermodynamic properties and particularly its response to pressure. The presence of $\mathrm{Fe}^{3+}-\mathrm{H}$ introduces distinctive high-frequency vibrations to the crystal. The frequency of these peaks is configuration dependence. Of the two defect configurations, $\left[\mathrm{Fe}_{\mathrm{Si}}^{\prime}+\mathrm{OH}^{-}\right]$makes large effects on the thermodynamic properties of Brg and PPv, whereas $\left[\mathrm{V}_{\mathrm{Mg}}^{\prime \prime}+\mathrm{Fe}_{\mathrm{Mg}}^{-}+\mathrm{OH}^{-}\right]$has negligible effects. With an expected lower mantle water concentrations of $<1000 \mathrm{wt}$. ppm the effect of $\mathrm{Fe}^{3+}-\mathrm{H}$ clusters on properties such as heat capacity and thermal expansion is negligible, but the effect on the Grüneisen parameter $\gamma$ can be significant $(\sim 1.2 \%)$. This may imply that even a small amount of water may affect the anharmonicity of $\mathrm{Fe}^{3+}$-bearing $\mathrm{MgSiO}_{3}$ in lower mantle conditions and that when calculating the adiabaticity of the mantle, water concentrations need to be considered.
\end{abstract}

Keywords: hydrogen; bridgmanite; post-perovskite; ferric iron; phonon vibration; thermodynamic property

\section{Introduction}

Iron-bearing bridgmanite (Brg) and its high-pressure phase post-perovskite (PPv) are thought to be the most abundant mineral phases in the Earth's lower mantle and D" layer along with ferropericlase $(\mathrm{Mg}, \mathrm{Fe}) \mathrm{O}$ and Calcium silicate perovskite $\mathrm{CaSiO}_{3}[1,2]$. Since the discovery of a phase transition from bridgmanite to post-perovskite [3-5] at relevant pressure and temperature conditions of the lowermost mantle, this has been invoked to explain some seismic features of the $\mathrm{D}^{\prime \prime}$ layer, such as the origin of $\mathrm{D}^{\prime \prime}$ and its seismic signals [6-8]. Hence, studying the vibrational and thermodynamic properties of Brg and $\mathrm{PPv}$ is critical to revealing the secret of the Brg-PPv phase transition and the thermal structure of the $\mathrm{D}^{\prime \prime}$ layer. Recent experimental and theoretical studies have shown that the phase transition from Brg to PPv can be very complicated in the presence of defect elements, particularly $\mathrm{Fe}$ and $\mathrm{Al}$, as they can both broaden the transition and change the depth at which it occurs [9-11].

While generally, the lower mantle is reductive, Fe can be incorporated into bridgmanite and post-perovskite in both the +2 (ferrous) and +3 (ferric) state, with the latter being favored in the presence of Aluminum at the high pressures and temperatures near the $\mathrm{D}^{\prime \prime}$ [12]. This is created through a disproportionation reaction of $\mathrm{Fe}^{2+}$ into $\mathrm{Fe}^{3+}$ and metallic Fe [13-15]. Experimental and theoretical studies demonstrate that $\mathrm{Fe}^{3+}$ can be incorporated into the lattice of lower mantle minerals either as $\mathrm{Fe}^{3+}-\mathrm{Fe}^{3+}$ pairs on the $\mathrm{Mg}(\mathrm{A})$ and $\mathrm{Si}$ (B) sites or as $\mathrm{Fe}^{3+}-\mathrm{Al}^{3+}$ pairs with $\mathrm{Fe}^{3+}$ on the $\mathrm{A}$ and $\mathrm{Al}^{3+}$ on the $\mathrm{B}$ though above $80 \mathrm{GPa}$ these preferences can be changed as some $\mathrm{Fe}^{3+}$ swaps to the $\mathrm{B}$ site and $\mathrm{Al}^{3+}$ to the $\mathrm{A}$ site $[2,16-19]$. 
Therefore, investigating the effects of impurities (such as $\mathrm{Fe}^{3+}$ ) on the vibrational and thermodynamic properties of bridgmanite and post-perovskite is important for better understanding and modeling the real lower mantle and D" layer region.

Since the discovery of post-perovskite and the Brg to PPv transition, the vibrational and thermodynamic properties of Mg-bearing bridgmanite and post-perovskite at lower mantle conditions have been explored intensively by experimental [20-22] and theoretical studies [23-26]. Recently, a series of studies have reported a wealth of results demonstrating the effects of $\mathrm{Al}$ or $\mathrm{Fe}$ on the vibrational and thermodynamic properties of $\mathrm{Brg}$ and PPv [27-30]. Those results greatly contribute to our understanding of the thermal structure, composition, and dynamic behavior of the lowermost mantle. However, given the multifarious volatiles present in the lower mantle [31,32], the effects of the complex chemical composition on the thermodynamic properties of the bridgmanite and post-perovskite are still not constrained well, in particular, the effects due to water $(\mathrm{H})$.

Previous studies on vibrational and thermodynamic properties have mainly focused on the dry system. Water (hydrogen), however, is an important volatile in the Earth's mantle and should be considered. It is believed that the transition zone has a high water content with up to $\sim 1-2 \mathrm{wt.} \%$, at least locally [33-35], but water content in the lower mantle is still controversial. Previous studies have suggested that the water content of lower mantle minerals would be no more than $\sim 20 \mathrm{ppm}$ [36,37]; however, some experiments have reported a wider water content range from $\sim 50 \mathrm{ppm}$ to $\sim 0.4 \mathrm{wt} . \%$ [38,39]. Recently, experimental and theoretical studies have indicated that the lower mantle minerals, bridgmanite, and post-perovskite, can potentially contain a relatively high amount of water with over 2000 ppm [40,41]. Water in minerals can have significant effects on their physical and chemical properties and thus on those of the Earth's mantle. The presence of water in $\mathrm{MgSiO}_{3}$ will affect the phase stability of bridgmanite and post-perovskite in lower mantle conditions. The phase transition boundary between bridgmanite and post-perovskite shifts to higher or lower pressures, respectively, when hydrogen atoms substitute in the $\mathrm{Mg}$ or Si sites in the lattice [42]. Furthermore, water combined with some cations can also influence the seismic properties of Brg and PPv. Our recent study has also found that the elastic properties of the $\mathrm{MgSiO}_{3}$ system, especially the shear velocity, are also remarkably sensitive to the presence of hydrogen in the Fe-bearing Brg and PPv [42]. The incorporation of $\mathrm{Fe}^{3+}$ and $\mathrm{H}$ in the $\mathrm{MgSiO}_{3}$ system via $\left[\mathrm{Fe}^{3+}-\mathrm{H}\right]_{\mathrm{Si}}$ defect $\left(\mathrm{Fe}_{\mathrm{Si}}^{\prime}+\mathrm{OH}^{-}\right)$can yield a shear velocity anomaly which is very close to the average anomaly value of LLSVPs from seismic observation. This may imply that hydrous $\mathrm{Fe}^{3+}$-bearing $\mathrm{MgSiO}_{3}$ is a dominant mineral in LLSVPs. The effects of water on the physical and chemical properties of $\mathrm{MgSiO}_{3}$, especially for Fe-bearing systems, need to be better constrained. Therefore, the influence of water on the vibrational and thermodynamic properties of bridgmanite and post-perovskite need to be determined further in order to better understand the thermodynamic and thermal structure of the lower mantle.

In this study, we use Density Functional Theory (DFT) in combination with the density functional perturbation theory (DFPT) method to investigate the effects of different hydrogen defect configurations on the vibrational phonon frequency of hydrous $\mathrm{Fe}^{3+}$-bearing bridgmanite and post-perovskite. We have also calculated in detail the thermodynamic parameters of hydrous $\mathrm{Fe}^{3+}$-bearing lower and $\mathrm{D}^{\prime \prime}$ layer minerals with different $\mathrm{Fe}^{3+}$ and $\mathrm{H}$ defect configurations using a quasi-harmonic approximation (QHA), and we have estimated the effects of hydrogen on the thermodynamic properties of $\mathrm{Fe}^{3+}$-bearing bridgmanite and post-perovskite.

\section{Computational Methods}

\subsection{Computational Details}

All simulations were carried out with the VASP code [43] using the all-electron projector-augmented-wave (PAW) method [44], and the electron exchange-correlation was described by the PBE form of Generalized Gradient Approximation (GGA) [45]. The used PBE potentials are $1 \mathrm{~S}^{2}$ core (radius 1.52 a.u.) for $\mathrm{O}, 1 \mathrm{~S}^{2} 2 \mathrm{~S}^{2}$ core (radius 2 a.u.) for 
$\mathrm{Mg}, 1 \mathrm{~s}^{2} 2 \mathrm{~s}^{2} 2 \mathrm{p}^{6}$ core (radius 1.9 a.u.) for $\mathrm{Si}, 1 \mathrm{~s}^{2} 2 \mathrm{~s}^{2} 2 \mathrm{p}^{6} 3 \mathrm{~s}^{2} 3 \mathrm{p}^{6}$ core (radius 2.3 a.u.) for Fe. GGA often cannot correctly describe the electronic structure of iron-containing systems as their d-electrons have strong correlations; therefore, we used a GGA+U functional to treat the iron. The Hubbard $\mathrm{U}$ term was set to $3 \mathrm{eV}$ following Hsu et al. [46] and Muir and Brodholt [47], which has already been successfully applied to describe the properties of iron-bearing systems at lower mantle conditions.

For all calculations, we used $(2 \times 2 \times 1)$ and $(4 \times 1 \times 1)$ supercells with 80 atoms for the bridgmanite $(\mathrm{Brg})$ phase and post-perovskite $(\mathrm{PPv})$ phase, respectively. In static runs, the plane-wave cutoff was set to $600 \mathrm{eV}$, and a $(3 \times 3 \times 4)$ Monkhorst-Pack grid [48] was used for the Brillouin zone sampling. All structures were fully relaxed at an imposed pressure of 30-150 GPa by using the conjugate-gradients method until the total energy differences were less than $10^{-6} \mathrm{eV}$. The force convergence criterion was set to $0.01 \mathrm{eV} / \AA$. After the structural optimizations, frequencies and force constant matrixes were calculated based on the density functional perturbation theory (DFPT) [49]. Phonon dispersion curves were obtained by using the PHONOPY code [50]. Gibbs free energy and high-temperature thermodynamic properties were then calculated using the quasi-harmonic approximation $(\mathrm{QHA})$ method with an $(11 \times 11 \times 11)$ q-point mesh.

\subsection{The Configurations of Hydrogen Defects and Spin State of Iron}

In this study, we considered two schemes of iron-bearing hydrogen defects: $\left[\mathrm{Fe}^{3+}-\mathrm{H}\right]_{\mathrm{Si}}$ defect $\left(\mathrm{Fe}_{\mathrm{Si}}^{\prime}+\mathrm{OH}^{-}\right)\left(0.552\right.$ wt. $\left.\% \mathrm{H}_{2} \mathrm{O}\right)$ and $\left[\mathrm{Fe}^{3+}-\mathrm{H}\right]_{\mathrm{Mg}-\mathrm{Mg}}$ defect $\left(\mathrm{V}_{\mathrm{Mg}}^{\prime \prime}+\mathrm{Fe}_{\mathrm{Mg}}^{-}+\mathrm{OH}^{-}\right)$ $\left(0.559 \mathrm{wt} . \% \mathrm{H}_{2} \mathrm{O}\right)$. These two iron-hydrogen defects configurations correspond to the case where $\left[\mathrm{Fe}^{3+}-\mathrm{H}\right]$ is in the Si site or the $\mathrm{Mg}$ site in the lattice, respectively. Thus, the effects of different occupations of hydrogen and iron on the vibrational and thermodynamic properties of minerals can be examined.

In the iron-bearing system, the spin state of $\mathrm{Fe}^{3+}$ needs to be determined to estimate the effect of the $\mathrm{Fe}^{3+}$ spin state on the properties of the mineral. For both bridgmanite and post-perovskite, experimental and theoretical studies have reported that the $\mathrm{Fe}^{3+}$ at the Mg-site is typically high spin (HS, S = 5/2) throughout the lower mantle region; however, the $\mathrm{Fe}^{3+}$ in a Si-site undergoes a spin transition from high spin (HS, $\left.\mathrm{S}=5 / 2\right)$ to low spin (LS, $S=1 / 2$ ) for both bridgmanite $[16,18,46]$ and post-perovskite $[17,51]$. Therefore, for the $\left[\mathrm{Fe}^{3+}-\mathrm{H}\right]_{\mathrm{Si}}$ defect, we set an initial $\mathrm{Fe}^{3+}$ spin state configuration with high spin (HS) and low spin (LS), respectively. For the $\left[\mathrm{Fe}^{3+}-\mathrm{H}\right]_{\mathrm{Mg}-\mathrm{Mg}}$ defect, its initial $\mathrm{Fe}^{3+}$ spin state was set to high spin (HS).

$\mathrm{HS} \mathrm{Fe}^{3+}$ and $\mathrm{LS} \mathrm{Fe}^{3+}$ can stabilize as a mixed spin state (MS) at lower mantle conditions due to magnetic and configurational entropy at high temperatures. In order to calculate the concentration of high and low spin iron under certain pressures and temperatures, we used the below equation:

$$
n_{L S}(P, T)=\frac{1}{1+\exp \left[\frac{\Delta \mathrm{G}_{L S-H S}}{k_{B} T n_{F e}}\right]}
$$

where $n_{L S}$ is the fraction of the low spin state, $\Delta \mathrm{G}$ is the difference between the free energy of low spin and high spin state, $n_{\mathrm{Fe}}$ is the number of iron atoms per unit cell and $k_{B}$ is the Boltzmann constant.

Magnetic entropy was included in the total free energy and was given by:

$$
S_{m a g}=-k_{B} n_{F e} \ln [m(2 S+1)]
$$

where $S$ is the iron spin quantum number ( $S=5 / 2$ for HS and $S=1 / 2$ for LS), and $m$ is the electronic configuration degeneracy ( $m=1$ for HS and $m=3$ for LS).

Placing defects in a crystal also creates configurational entropy. This configurational entropy can be calculated by using Boltzmann's entropy formula:

$$
S_{\text {conf }}=k_{B} \ln \Omega
$$




$$
\Omega=\frac{N !}{\left(n_{i}\right) !\left(N-n_{i}\right) !}
$$

where $\Omega$ represents the number of possible configurations of the impurity atom, $N$ is the number of possible crystallographic sites of the impurity atom, and $n_{i}$ is the number of impurity atoms $\left(\mathrm{Fe}^{3+}\right.$ and $\left.\mathrm{H}\right)$.

\section{Results and Discussion}

\subsection{Incorporation of Hydrogen and Ferric}

It has been previously reported that ferric iron $\left(\mathrm{Fe}^{3+}\right)$ typically occupies the $\mathrm{Mg}$-site (Asite) in Al-bearing $\mathrm{MgSiO}_{3}$, and in $\mathrm{Al}$-free $\mathrm{MgSiO}_{3}$, ferric iron occupies both the $\mathrm{Mg}$ and the Si-site (B-site) [17,52]. In addition, water can be incorporated into a cationic vacancy (Mg site or $\mathrm{Si}$ site) in a $\mathrm{MgSiO}_{3}$ lattice as a hydrogen defect via a charge-coupled substitution mechanism [53-55]. Therefore, two different hydrous states were considered in this study: a $\left[\mathrm{Fe}^{3+}-\mathrm{H}\right]_{\mathrm{Si}}$ defect that simulates the interaction of water with a Fe${ }^{3+}$ in a Si octahedral site (B-site), and an $\left[\mathrm{Fe}^{3+}-\mathrm{H}\right]_{\mathrm{Mg}-\mathrm{Mg}}$ defect which simulates the interaction of water with $\mathrm{Fe}^{3+}$ in an $\mathrm{Mg}$ dodecahedral site (A-site). The stable local arrangement of the $\mathrm{Fe}^{3+}$ and the $\mathrm{H}$ atom in $\mathrm{MgSiO}_{3}$ lattice is that for the $\left[\mathrm{Fe}^{3+}-\mathrm{H}\right]_{\mathrm{Si}}$ defect, a Fe ${ }^{3+}$ and an $\mathrm{H}$ atom occupy a Si-site by replacing the $\mathrm{Si}$ atom with a coupled pair, whereby the $\mathrm{H}$ atom bonds with an $\mathrm{O} 1$ atom in the $\mathrm{SiO}_{6}$ octahedron (Supplementary Materials Figures S1 and S2). For the $\left[\mathrm{Fe}^{3+}-\mathrm{H}\right]_{\mathrm{Mg}-\mathrm{Mg}}$ defect, a Fe ${ }^{3+}$ atom and an $\mathrm{H}$ atom occupy two nearest $\mathrm{Mg}$-site by replacing two $\mathrm{Mg}$ atoms respectively, and the $\mathrm{H}$ atom also bonds with an $\mathrm{O} 1$ atom (Supplementary Materials Figure S3 and S4). For all defect structures, we have eliminated from consideration those structures that have unstable phonon spectrums and unfeasibly high enthalpies [42].

We have calculated the energy of $\mathrm{Fe}^{3+}$-bearing $\mathrm{MgSiO}_{3}$ with different $\mathrm{Fe}^{3+}$ and $\mathrm{H}$ defects in our previous study [42] to evaluate the relative stability of $\mathrm{Fe}^{3+}$ and $\mathrm{H}$ defects in Fe-bearing systems for both Brg and PPv phases. We assumed that the exchange between $\left[\mathrm{Fe}^{3+}-\mathrm{H}\right]_{\mathrm{Si}}$ and $\left[\mathrm{Fe}^{3+}-\mathrm{H}\right]_{\mathrm{Mg}-\mathrm{Mg}}$ defect in the lattice can be represented by the following reaction:

$$
\left(\mathrm{Mg}_{1-2 x} \mathrm{Fe}_{x} \mathrm{H}_{x}\right) \mathrm{SiO}_{3}+3 x \mathrm{MgO} \Longleftrightarrow \mathrm{Mg}\left(\mathrm{Si}_{1-x} \mathrm{Fe}_{x} \mathrm{H}_{x}\right) \mathrm{O}_{3}+x \mathrm{MgSiO}_{3}
$$

The left-hand side of the above reaction represents $\mathrm{Fe}^{3+}$ and $\mathrm{H}$ in the $\mathrm{Mg}$ site $\left(\left[\mathrm{Fe}^{3+}\right.\right.$ $\left.\mathrm{H}]_{\mathrm{Mg}-\mathrm{Mg}}\right)$, and the right-hand side is $\mathrm{Fe}^{3+}$ and $\mathrm{H}$ in the Si site $\left(\left[\mathrm{Fe}^{3+}-\mathrm{H}\right]_{\mathrm{Si}}\right)$. The reaction enthalpies $\Delta \mathrm{H}$ of reaction (5) have been calculated in our recent study [42]. For both the $\mathrm{Brg}$ and $\mathrm{PPv}$ phase, the reaction enthalpies decrease with increasing pressure, and the values of $\Delta \mathrm{H}$ are negative at all lower mantle pressures, indicating favorably for $\left[\mathrm{Fe}^{3+}-\mathrm{H}\right]_{\mathrm{Si}}$. This was calculated at $x=0.0625$ but likely holds for all concentrations as $\Delta \mathrm{H}$ should be roughly linear with concentration and should not change significantly until very high concentrations are reached, and the entropy is the same if $\mathrm{Fe}-\mathrm{H}$ is in a $\mathrm{Si}$ or an $\mathrm{Mg}$ site. Thus, we predict that, in a hydrous $\mathrm{Fe}^{3+}$-bearing $\mathrm{MgSiO}_{3}$ system, the $\left[\mathrm{Fe}^{3+}-\mathrm{H}\right]_{\mathrm{Si}}$ defect is energetically more stable compared with $\left[\mathrm{Fe}^{3+}-\mathrm{H}\right]_{\mathrm{Mg}-\mathrm{Mg}}$ defect at all lower mantle pressures and conditions in both Brg and PPv.

\subsection{Vibrational Properties}

The vibrational properties of $\left[\mathrm{Fe}^{3+}-\mathrm{H}\right]_{\mathrm{Si}^{-}} \mathrm{Brg} / \mathrm{PPv}$ and $\left[\mathrm{Fe}^{3+}-\mathrm{H}\right]_{\mathrm{Mg}-\mathrm{Mg}}-\mathrm{Brg} / \mathrm{PPv}$ are investigated by calculating the phonon dispersion curves and vibrational density of states (VDoS) up to $150 \mathrm{GPa}$, and all results are given in Figures 1 and 2 and Figures S5-S8. The pure Brg and PPv phase has 20 atoms per primitive cell, so there are 60 vibrational modes at each $q$ point in the Brillouin zone. However, the presence of ferric and hydrogen will break the symmetry of lattice and lead to 243 and 240 vibrational modes in the $\left[\mathrm{Fe}^{3+}-\mathrm{H}\right]_{\mathrm{Si}}$ (81 atoms) and $\left[\mathrm{Fe}^{3+}-\mathrm{H}\right]_{\mathrm{Mg}-\mathrm{Mg}}(80$ atoms) supercells, respectively. In general, the addition of Fe has been predicted to soften the acoustic phonon modes [27], and we predict that this will still occur, especially at the $\mathrm{T}$ and R points. For example, at $60 \mathrm{GPa}$, the lowest acoustic phonon frequency at the T point is softened, from $\sim 191.5 \mathrm{~cm}^{-1}$ and $\sim 185.2 \mathrm{~cm}^{-1}$ 
for pure-Brg and pure-PPv to $\sim 116.1 \mathrm{~cm}^{-1}$ and $\sim 96.0 \mathrm{~cm}^{-1}$ for $\left[\mathrm{Fe}^{3+}-\mathrm{H}\right]_{\mathrm{Si}}-\mathrm{Brg}$ and PPv, respectively. In addition, at the $\mathrm{R}$ point and at the same pressure, the lowest frequency decreases from $\sim 225.8 \mathrm{~cm}^{-1}$ for pure-Brg and $\sim 208.0 \mathrm{~cm}^{-1}$ for pure-PPv to $\sim 110.7 \mathrm{~cm}^{-1}$ for $\left[\mathrm{Fe}^{3+}-\mathrm{H}\right]_{\mathrm{Si}}-\mathrm{Brg}$ and $\sim 96.3 \mathrm{~cm}^{-1}$ for $\left[\mathrm{Fe}^{3+}-\mathrm{H}\right]_{\mathrm{Si}}-\mathrm{PPv}$.
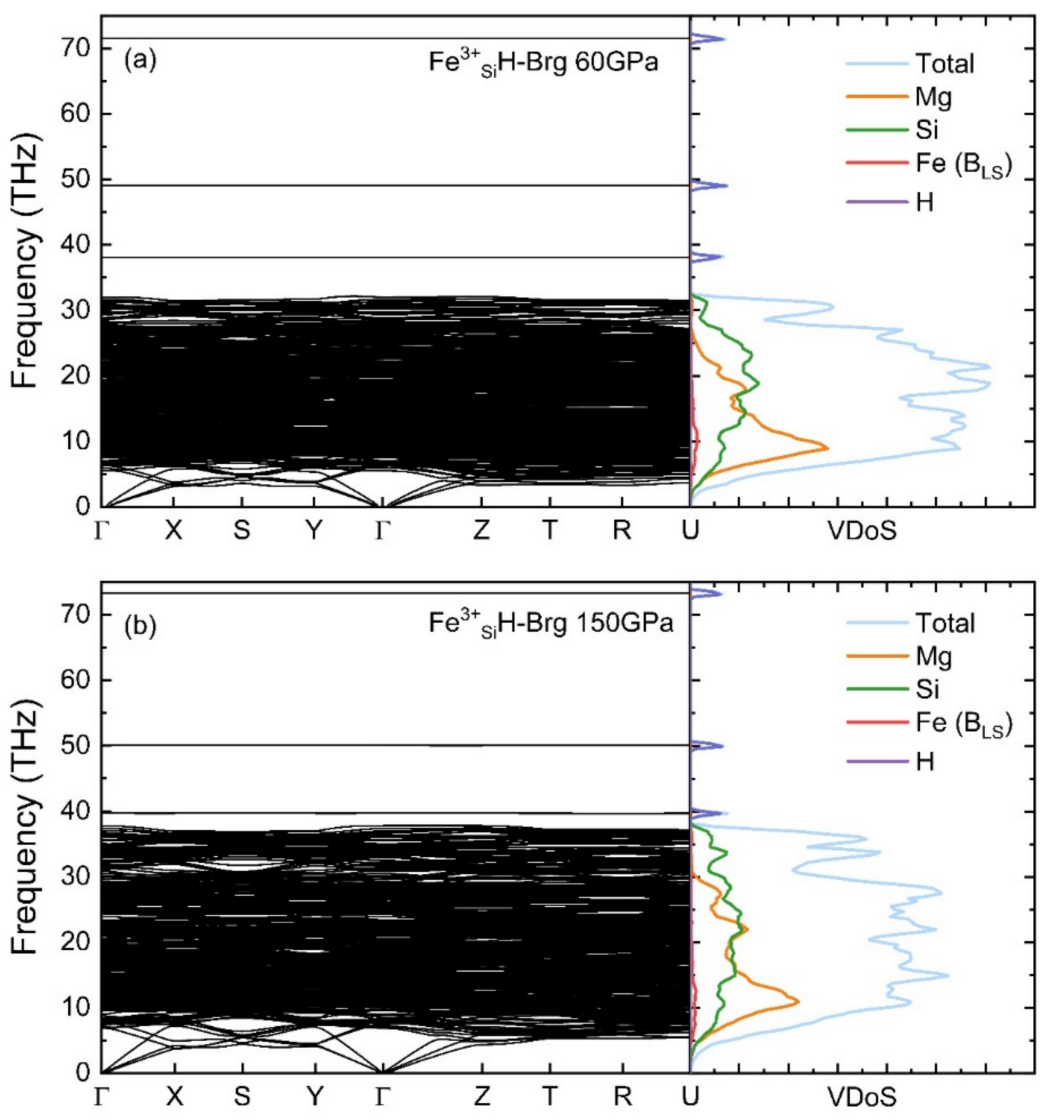

Figure 1. Phonon dispersion curves and vibrational density of states (VDoS) of $\left[\mathrm{Fe}^{3+}-\mathrm{H}\right]_{\mathrm{Si}^{-}}-\mathrm{Brg}$ with LS Fe ${ }^{3+}$ at $60 \mathrm{GPa}(\mathbf{a})$ and $150 \mathrm{GPa}(\mathbf{b})$, respectively. $\mathrm{B}_{\mathrm{LS}}$ indicates low spin $\mathrm{Fe}^{3+}$ in B site (Si site). Total VDoS and partial VDoS of Mg, Si, Fe (LS), H are shown by light blue, orange, green, red, and purple, respectively.

The phonon dispersion curves and partial VDoS at 60 and $150 \mathrm{GPa}$ for $\left[\mathrm{Fe}^{3+}-\mathrm{H}\right]_{\mathrm{Si}}-\mathrm{Brg}$ with LS and HS ferric iron are shown in Figure 1 and Supplementary Materials Figure S5, and for $\left[\mathrm{Fe}^{3+}-\mathrm{H}\right]_{\mathrm{Si}}-\mathrm{PPv}$ with LS and HS ferric are shown in Figures S6 and S7, respectively. Both $\left[\mathrm{Fe}^{3+}-\mathrm{H}\right]_{\mathrm{Si}}$ and $\left[\mathrm{Fe}^{3+}-\mathrm{H}\right]_{\mathrm{Mg}-\mathrm{Mg}}$ bridgmanites contain only real frequencies, which indicates these structures are dynamically stable across lower mantle pressures (>30 GPa). Under $30 \mathrm{GPa}$, the PPv structures have negative frequencies as PPv is unfavored by low pressure. In $\left[\mathrm{Fe}^{3+}-\mathrm{H}\right]_{\mathrm{Si}}-\mathrm{Brg}$, the phonon dispersion curves and partial VDoS indicate that $\mathrm{Fe}^{3+}$ mainly affects the low phonon frequency parts of the spectrum and that three distinctive phonons are created at high frequencies, which uniquely identify the $\left[\mathrm{Fe}^{3+}\right.$ $\mathrm{H}]_{S i}$ structure. According to the phonon dispersion curves at different pressures (i.e., Figure $1 \mathrm{a}, \mathrm{b})$, the phonon frequencies are increased with increasing pressure at nearly every $q$ point, which is consistent with the previous study of dry Fe-bearing bridgmanite [29]. The high-frequency phonons that are related to hydrogen are also affected by the spin state of $\mathrm{Fe}^{3+}$, as displayed in Figure $1 \mathrm{~b}$ and Supplementary Materials Figure S5b. At $150 \mathrm{GPa}$, the highest frequency optic mode at the $\Gamma$ point is slightly increased from $\sim 72.2 \mathrm{THz}$ $\left(\sim 2408.4 \mathrm{~cm}^{-1}\right)$ for HS to $\sim 73.3 \mathrm{THz}\left(\sim 2445.1 \mathrm{~cm}^{-1}\right)$ for LS. In $\left[\mathrm{Fe}^{3+}-\mathrm{H}\right]_{\mathrm{Si}}-\mathrm{PPv}, \mathrm{Fe}^{3+}$ and hydrogen still contribute to the low and high phonon frequency parts of the system, respectively (Figures S6 and S7). The response of phonon frequencies to pressure is similar to the case of $\left[\mathrm{Fe}^{3+}-\mathrm{H}\right]_{\mathrm{Si}}-\mathrm{Brg}$; with increasing pressure, the phonon frequencies of $\left[\mathrm{Fe}^{3+}-\right.$ 
$\mathrm{H}]_{\mathrm{Si}^{-}} \mathrm{PPv}$ are raised. The effect of the $\mathrm{Fe}^{3+}$ spin state on the phonon frequencies of hydrogen in $\left[\mathrm{Fe}^{3+}-\mathrm{H}\right]_{\mathrm{Si}^{i}}-\mathrm{PPv}$ is opposite to that of $\left[\mathrm{Fe}^{3+}-\mathrm{H}\right]_{\mathrm{Si}^{-}}-\mathrm{Brg}$. The highest phonon frequency of hydrogen at the $\Gamma$ point is decreased from $\sim 64.1 \mathrm{THz}\left(\sim 2138.1 \mathrm{~cm}^{-1}\right)$ for an HS ferric iron to $\sim 58.7 \mathrm{THz}\left(\sim 1958.1 \mathrm{~cm}^{-1}\right)$ for LS at $150 \mathrm{GPa}$ (Figures S6b and S7b).
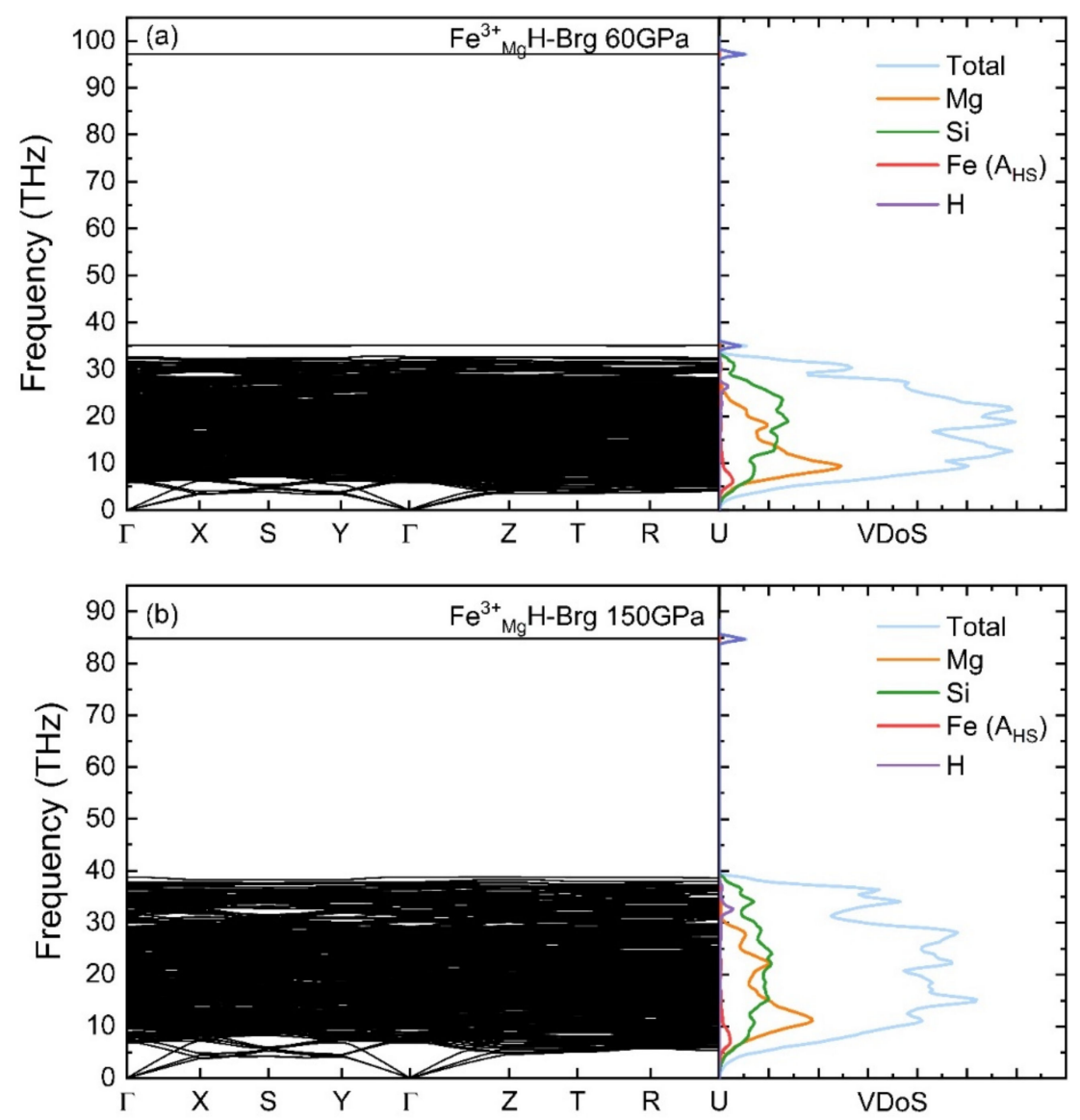

Figure 2. Phonon dispersion curves and vibrational density of states (VDoS) of $\left[\mathrm{Fe}^{3+}-\mathrm{H}\right]_{\mathrm{Mg}-\mathrm{Mg}}-\mathrm{Brg}$ at $60 \mathrm{GPa}(\mathbf{a})$ and $150 \mathrm{GPa}(\mathbf{b})$, respectively. $\mathrm{A}_{\mathrm{HS}}$ indicates high spin $\mathrm{Fe}^{3+}$ in A site (Mg site). Total VDoS and partial VDoS of Mg, Si, Fe (HS), $\mathrm{H}$ are shown by light blue, orange, green, red, and purple, respectively.

In the case of $\left[\mathrm{Fe}^{3+}-\mathrm{H}\right]_{\mathrm{Mg}-\mathrm{Mg}}$ defect configuration, the phonon dispersion curves and partial VDoS at 60 and $150 \mathrm{GPa}$ for $\left[\mathrm{Fe}^{3+}-\mathrm{H}\right]_{\mathrm{Mg}-\mathrm{Mg}}-\mathrm{Brg}$ and $\left[\mathrm{Fe}^{3+}-\mathrm{H}\right]_{\mathrm{Mg}-\mathrm{Mg}}-\mathrm{PPv}$ are displayed in Figure 2 and Supplementary Materials Figure S8, respectively. The presence of $\mathrm{Fe}^{3+}$ and hydrogen also affect the low and high phonon frequency parts in both $\left[\mathrm{Fe}^{3+}-\right.$ $\mathrm{H}]_{\mathrm{Mg}-\mathrm{Mg}}-\mathrm{Brg}$ and $\left[\mathrm{Fe}^{3+}-\mathrm{H}\right]_{\mathrm{Mg}-\mathrm{Mg}}-\mathrm{PPv}$. In $\left[\mathrm{Fe}^{3+}-\mathrm{H}\right]_{\mathrm{Mg}-\mathrm{Mg}}-\mathrm{Brg}$, the frequency of the phonons with low and middling phonon frequencies parts of the system increase with increasing pressure but the $\mathrm{H}$-associated phonons with high frequencies decrease with pressure, as shown in Figure 2a,b. The highest hydrogen phonon frequencies at the $\Gamma$ point are $\sim 97.2 \mathrm{THz}\left(\sim 3242.2 \mathrm{~cm}^{-1}\right)$ for $60 \mathrm{GPa}$ and $\sim 84.7 \mathrm{THz}\left(2825.3 \mathrm{~cm}^{-1}\right)$ for $150 \mathrm{GPa}$. These are considerably larger than those seen for the $\left[\mathrm{Fe}^{3+}-\mathrm{H}\right]_{\mathrm{Si}}$ defect configuration and provide a way of distinguishing between these configurations. In $\left[\mathrm{Fe}^{3+}-\mathrm{H}\right]_{\mathrm{Mg}-\mathrm{Mg}}-\mathrm{PPv}$, the frequencies have similar responses to pressure as with $\left[\mathrm{Fe}^{3+}-\mathrm{H}\right]_{\mathrm{Mg}-\mathrm{Mg}}-\mathrm{Brg}$, and also have higher phonon frequencies than those of $\left[\mathrm{Fe}^{3+}-\mathrm{H}\right]_{\mathrm{Si}}-\mathrm{PPv}$ (Supplementary Materials Figure S8a,b). 


\subsection{Thermodynamic Properties}

On the base of calculated phonon frequencies, the Gibbs free energy can be obtained within the QHA frame, then the fundamental thermodynamic properties for $\left[\mathrm{Fe}^{3+}-\mathrm{H}\right]_{\mathrm{Si}^{-}}$ $\mathrm{Brg} / \mathrm{PPv}$ and $\left[\mathrm{Fe}^{3+}-\mathrm{H}\right]_{\mathrm{Mg}-\mathrm{Mg}}-\mathrm{Brg} / \mathrm{PPv}$ are derived from the Helmholtz free energy with standard thermodynamic relations at specific temperatures and pressures [56]. The isothermal bulk modulus $K_{T}$, thermal expansion coefficient $\alpha$, isochoric $C_{V}$ and isobaric heat capacities $C_{P}$, Grüneisen parameter $\gamma$ and the vibrational contribution to the entropy $S_{\text {vib }}$ are shown in Figure 3 and Supplementary Materials Table S1 for the Brg-phase, and Figure 4 and Supplementary Materials Table S2 for the PPv-phase, respectively.
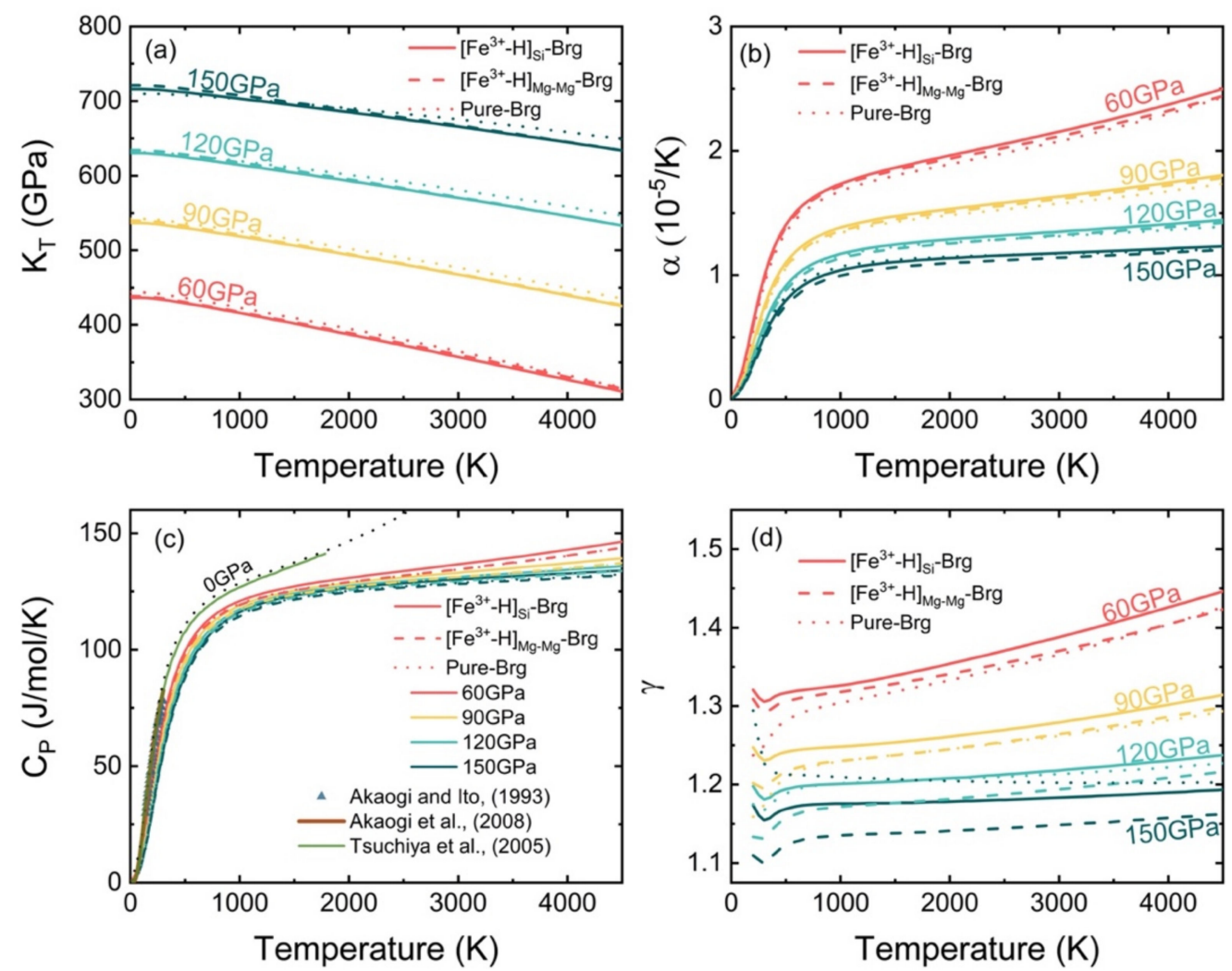

Figure 3. The thermodynamic properties of hydrous $\mathrm{Fe}^{3+}$-bearing Brg as a function of temperature at different pressures. (a) Isothermal bulk modulus, (b) Thermal expansivity, (c) isobaric heat capacity, (d) Grüneisen parameter. Solid, dashed, and dotted lines represent the $\left[\mathrm{Fe}^{3+}-\mathrm{H}\right]_{\mathrm{Si}}-\mathrm{Brg}$, $\left[\mathrm{Fe}^{3+}-\mathrm{H}\right]_{\mathrm{Mg}-\mathrm{Mg}}-\mathrm{Brg}$, and Pure- $\mathrm{Brg}$, respectively. The experimental values (blue triangle and brown line) are from Akaogi and Ito [57] and Akaogi et al. [58]. The previous theoretical results (green line) are from Tsuchiya et al. [25]. 

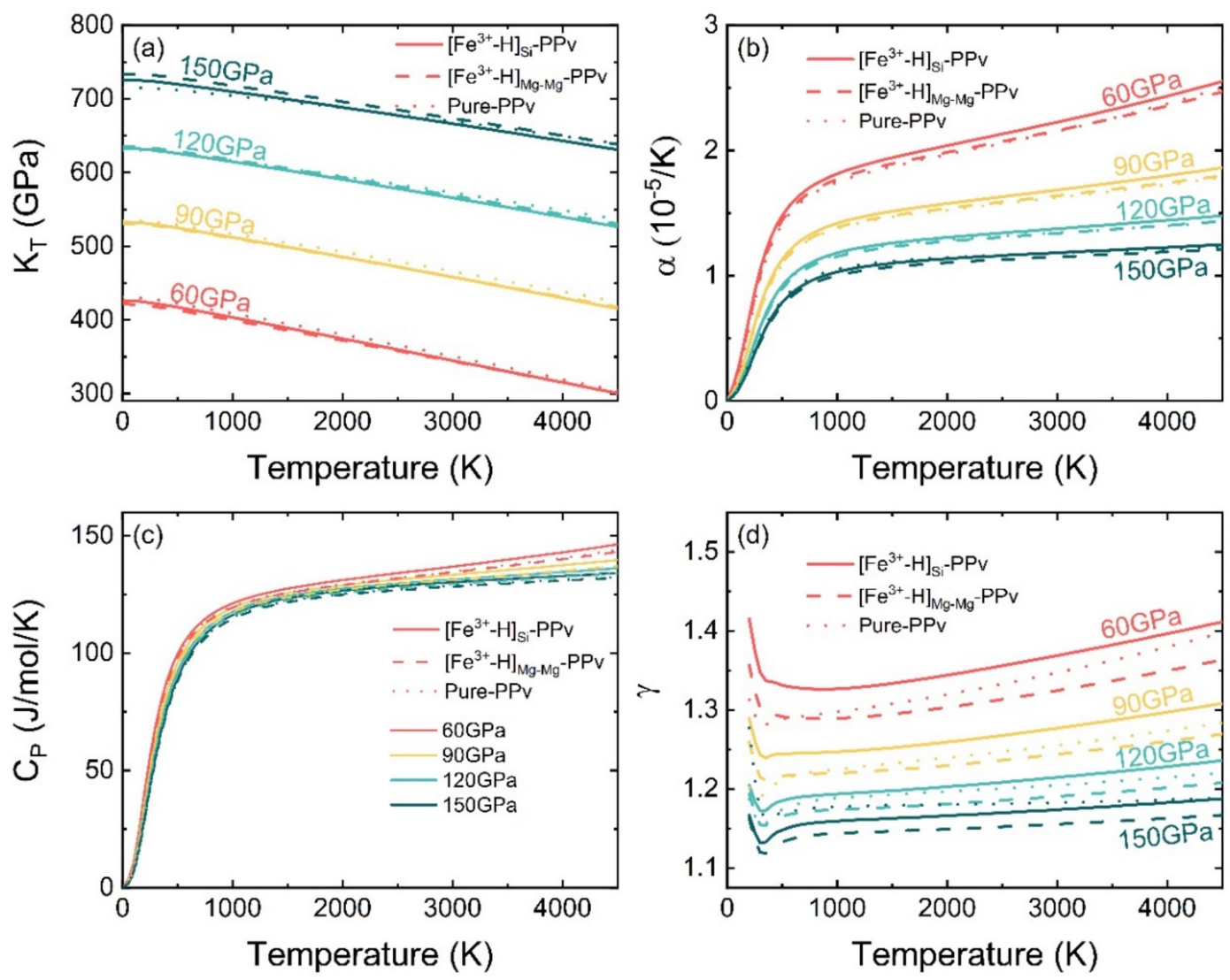

Figure 4. The thermodynamic properties of hydrous $\mathrm{Fe}^{3+}$-bearing PPv as a function of temperature at different pressures. (a) Isothermal bulk modulus, (b) Thermal expansivity, (c) isobaric heat capacity, (d) Grüneisen parameter. Solid, dashed, and dotted lines represent the $\left[\mathrm{Fe}^{3+}-\mathrm{H}\right]_{\mathrm{Si}}-\mathrm{PPv},\left[\mathrm{Fe}^{3+}-\mathrm{H}\right]_{\mathrm{Mg}-\mathrm{Mg}}-\mathrm{PPv}$, and Pure- $\mathrm{PPv}$, respectively.

At finite temperature, $\mathrm{Fe}^{3+}$ can be stabilized as a mixed spin state (MS) of high and low spins, and this can occur at lower mantle conditions. To calculate the thermodynamic properties when the iron is in a mixed spin state, we took the values of the properties calculated at HS and LS and calculated an average weighted by $n_{L S}$ obtained from Equation (1). Calculated low spin state fraction $\left(n_{L S}\right)$ of $\mathrm{Fe}^{3+}$ in $\left[\mathrm{Fe}^{3+}-\mathrm{H}\right]_{\mathrm{Si}}-\mathrm{Brg}$ and $\left[\mathrm{Fe}^{3+}-\mathrm{H}\right]_{\mathrm{Si}^{-}}-\mathrm{PPv}$ at specific pressures and temperatures are listed in Table 1.

Table 1. Calculated low spin state fraction $\left(n_{L S}\right)$ of Ferric $\left(\mathrm{Fe}^{3+}\right)$ in $\left[\mathrm{Fe}^{3+}-\mathrm{H}\right]_{\mathrm{Si}^{-}}-\mathrm{Brg}$ and $\left[\mathrm{Fe}^{3+}-\mathrm{H}\right]_{\mathrm{Si}^{-}}-\mathrm{PPv}$, respectively, at specific pressure and temperature.

\begin{tabular}{cccccc}
\hline Configuration & Temperature & $\mathbf{6 0 ~ G P a}$ & $\mathbf{9 0 ~ G P a}$ & $\mathbf{1 2 0 ~ G P a}$ & $\mathbf{1 5 0 ~ G P a}$ \\
\hline & $300 \mathrm{~K}$ & 1 & 1 & 1 & 1 \\
{$\left[\mathrm{Fe}^{3+}-\mathrm{H}\right]_{\mathrm{Si}^{-}}$} & $1000 \mathrm{~K}$ & 0.94 & 1 & 1 & 1 \\
$\mathrm{Brg}$ & $2000 \mathrm{~K}$ & 0.62 & 0.97 & 1 & 1 \\
& $3000 \mathrm{~K}$ & 0.41 & 0.86 & 0.97 & 0.99 \\
& $4000 \mathrm{~K}$ & 0.29 & 0.72 & 0.91 & 0.97 \\
\hline$\left[\mathrm{Fe}^{3+}-\mathrm{H}\right]_{\mathrm{Si}^{-}}$ & $300 \mathrm{~K}$ & 1 & 1 & 1 & 1 \\
$\mathrm{PPv}$ & $1000 \mathrm{~K}$ & 1 & 1 & 1 & 1 \\
& $2000 \mathrm{~K}$ & 0.92 & 0.99 & 1 & 1 \\
& $3000 \mathrm{~K}$ & 0.72 & 0.94 & 0.99 & 0.98 \\
\hline
\end{tabular}

The isothermal bulk moduli $K_{T}$ of the $\mathrm{Fe}^{3+}$-bearing hydrous system as a function of temperature at a specific pressure are displayed in Figure 3a for Brg-phase and Figure 4a for PPv-phase. For the Brg-phase (Figure 3a and Supplementary Materials Table S1), the presence of ferric and hydrogen reduce the $K_{T}$ compared with pure-Brg at the lower mantle 
P-T range. For instance, at $90 \mathrm{GPa}$ and $2000 \mathrm{~K},\left[\mathrm{Fe}^{3+}-\mathrm{H}\right]_{\mathrm{Si}^{-}}-\mathrm{Brg}$ and $\left[\mathrm{Fe}^{3+}-\mathrm{H}\right]_{\mathrm{Mg}-\mathrm{Mg}}-\mathrm{Brg}$ reduce the $K_{T}$ by $\sim 1.7 \%$ and $\sim 1.5 \%$ compared to pure-Brg, respectively. Meanwhile, this contrast on the $K_{T}$ will increase with temperature for both $\left[\mathrm{Fe}^{3+}-\mathrm{H}\right]_{\mathrm{Si}}-\mathrm{Brg}$ and $\left[\mathrm{Fe}^{3+}-\mathrm{H}\right]_{\mathrm{Mg}-\mathrm{Mg}}-\mathrm{Brg}$. At $4000 \mathrm{~K}$, the differences of $K_{T}$ between $\left[\mathrm{Fe}^{3+}-\mathrm{H}\right]$-bearing and pure system are raised to $-2.2 \%$ for $\left[\mathrm{Fe}^{3+}-\mathrm{H}\right]_{\mathrm{Si}}-\mathrm{Brg}$ and $-1.9 \%$ for $\left[\mathrm{Fe}^{3+}-\mathrm{H}\right]_{\mathrm{Mg}-\mathrm{Mg}}-\mathrm{Brg}$. On the other hand, the contrast of $K_{T}$ between $\left[\mathrm{Fe}^{3+}-\mathrm{H}\right]_{\mathrm{Si}^{-}}-\mathrm{Brg}$ and $\left[\mathrm{Fe}^{3+}-\mathrm{H}\right]_{\mathrm{Mg}-\mathrm{Mg}}-\mathrm{Brg}$ is marginal, which indicates that the $K_{T}$ is only slightly affected by $\left[\mathrm{Fe}^{3+}-\mathrm{H}\right]$ defect configuration $\left(\left[\mathrm{Fe}^{3+}-\mathrm{H}\right]\right.$ at $\mathrm{Mg}$ site or Si site). This data can be compared to that of pure iron, which is $\sim 2.0 \%$ [29] for the same concentration of iron. The effect of hydrogen is, therefore, to lessen the effect of iron on the modulus and allows iron to be partitioned into bridgmanite without having a large effect on the seismic properties.

For PPv, its isothermal bulk moduli $K_{T}$ is also decreased by the incorporation of $\mathrm{Fe}^{3+}$ and hydrogen (Figure 4a and Supplementary Materials Table S2). Compared to the pure-PPv, at $120 \mathrm{GPa}$ and $2000 \mathrm{~K},\left[\mathrm{Fe}^{3+}-\mathrm{H}\right]_{\mathrm{Si}}$ and $\left[\mathrm{Fe}^{3+}-\mathrm{H}\right]_{\mathrm{Mg}-\mathrm{Mg}}$ defect reduce the $K_{T}$ of the PPv-phase by $\sim 0.7 \%$ and $\sim 0.3 \%$, respectively. This effect reverses with pressure; however, at $150 \mathrm{GPa},\left[\mathrm{Fe}^{3+}-\mathrm{H}\right]_{\mathrm{Si}}-\mathrm{PPv}$ has a $K_{T}$ that is $\sim 0.8 \%$ higher than that of pure-PPv when the temperature is lower than $2000 \mathrm{~K}$. The increasing temperature lowers the $K_{T}$ of the hydrous $\mathrm{PPv}$, which is the same with Brg. Similarly, the $K_{T}$ of $\left[\mathrm{Fe}^{3+}-\mathrm{H}\right]_{\mathrm{Mg}-\mathrm{Mg}}-\mathrm{PPv}$ is larger than pure-PPv's at $150 \mathrm{GPa}$ and the temperature of up to $3900 \mathrm{~K}$.

In general, $\mathrm{Fe}-\mathrm{H}$ only makes a small change to the $K_{T}$ of $\mathrm{Brg}$ and PPv and a smaller change than that to pure iron, softening its effect. In the deep mantle where $\mathrm{Fe}-\mathrm{H}$ is expected to be relevant, the presence of such defects reduces the $K_{T}$ of both $\mathrm{Brg}$ and $\mathrm{PPv}$ due to the high temperature. The $K_{T}$ of Brg is reduced more than the $K_{T}$ of PPv by $\sim 0.8 \%$. If we scale this to an expected mantle composition of $\sim 1000 \mathrm{wt}$. ppm then this induces an anomaly of $0.2 \%$ across the Brg to PPv phase transition.

The thermal expansion coefficient $\alpha$ of the Brg-phase and PPv-phase at different pressures are determined by $\alpha=1 / V(\partial V / \partial T)_{P}$, and are plotted in Figures $3 \mathrm{~b}$ and $4 \mathrm{~b}$ as a function of temperature. The detailed values of the thermal expansion coefficient are listed in Supplementary Materials Tables S1 and S2. At lower mantle conditions such as at $90 \mathrm{GPa}$ and $2000 \mathrm{~K}$, the $\alpha$ of $\left[\mathrm{Fe}^{3+}-\mathrm{H}\right]_{\mathrm{Si}^{-}}-\mathrm{Brg}$ and $\left[\mathrm{Fe}^{3+}-\mathrm{H}\right]_{\mathrm{Mg}-\mathrm{Mg}}-\mathrm{Brg}$ are $\sim 1.53 \times 10^{-5} \mathrm{~K}^{-1}$ and $\sim 1.51 \times 10^{-5} \mathrm{~K}^{-1}$, respectively, which are larger than that of pure-Brg with a value of $1.48 \times 10^{-5} \mathrm{~K}^{-1}$ (Supplementary Materials Table S1). With increasing pressure, the difference between the hydrous and the pure system is reduced (Figure 3b), at $150 \mathrm{GPa}$ and $2000 \mathrm{~K},\left[\mathrm{Fe}^{3+}-\mathrm{H}\right]_{\mathrm{Si}}-\mathrm{Brg}$ has an $\alpha$ which almost equal to the value of pure-Brg. In addition, compared to the $\left[\mathrm{Fe}^{3+}-\mathrm{H}\right]_{\mathrm{Mg}-\mathrm{Mg}}-\mathrm{Brg}$, $\left[\mathrm{Fe}^{3+}-\mathrm{H}\right]_{\mathrm{Si}}-\mathrm{Brg}$ always has a larger $\alpha$ at the investigated P-T range. This has a small effect of around $1.0 \%$ on the density of the system. This is important because a small change of density is needed for LLSVPs. Large changes in density will call large changes to seismic velocities and likely get segregated to the bottom of the mantle. Very similar trends are seen in the PPv phase with $\left[\mathrm{Fe}^{3+}-\mathrm{H}\right]_{\mathrm{Si}^{-}} \mathrm{PPv}$ increasing $\alpha$ from $\sim 1.28 \times 10^{-5} \mathrm{~K}^{-1}$ to $\sim 1.31 \times 10^{-5} \mathrm{~K}^{-1}$ at $120 \mathrm{GPa}$ and $2000 \mathrm{~K}$ but this increase decreases with pressure while $\left[\mathrm{Fe}^{3+}-\mathrm{H}\right]_{\mathrm{Mg}-\mathrm{Mg}}$ makes no large change to $\alpha$. Across the Brg to $\mathrm{PPv}$ transition, the presence of $\left[\mathrm{Fe}^{3+}-\mathrm{H}\right]_{\mathrm{Si}}$ makes small difference to the density change of the transition $\left(\sim 1.3 \%\right.$ at $\mathrm{D}^{\prime \prime}$ layer depth) and thus does not substantially impact the rheological stability of the $\mathrm{D}^{\prime \prime}$ layer.

The isobaric heat capacities $C_{P}$ calculated from $C_{P}=-T\left(\partial^{2} G / \partial T^{2}\right)_{P}$ are shown in Figure $3 \mathrm{c}$ and Supplementary Materials Table S1 for the Brg-phase and Figure $4 \mathrm{c}$ and Supplementary Materials Table S2 for the PPv-phase, respectively. The isobaric heat capacities of pure-Brg calculated at $0 \mathrm{GPa}$ are in good agreement with the results from experimental studies [57,58], especially at around $300 \mathrm{~K}$. Moreover, comparing the $C_{P}$ we calculated and the data from other theoretical study, the value of $C_{P}$ of pure-Brg at $0 \mathrm{GPa}$ are fairly close to the results predicted by Tsuchiya, Tsuchiya, and Wentzcovitch [25]. This indicate that the thermodynamic parameters we predicted in this study are reasonable. At the pressure higher than $0 \mathrm{GPa}$, the $C_{P}$ of the Brg-phase is increased by the incorporation of $\mathrm{Fe}^{3+}$ and hydrogen via a $\left[\mathrm{Fe}^{3+}-\mathrm{H}\right]_{\mathrm{Si}}$ defect, especially at temperatures higher than $2500 \mathrm{~K}$. 
However, the Brg-phase's $C_{P}$ is not modified by the presence of the $\left[\mathrm{Fe}^{3+}-\mathrm{H}\right]_{\mathrm{Mg}-\mathrm{Mg}}$ defect (change is on average $\sim-0.1 \%$ ) (Figure $3 \mathrm{c}$ and Supplementary Materials Table S1). In the case of the PPv-phase, $\left[\mathrm{Fe}^{3+}-\mathrm{H}\right]_{\mathrm{Si}}-\mathrm{PPv}$ has a larger $C_{P}\left(127.5 \mathrm{~J} \cdot \mathrm{mol}^{-1} \cdot \mathrm{K}^{-1}\right)$ than pure-PPv $\left(125.9 \mathrm{~J} \cdot \mathrm{mol}^{-1} \cdot \mathrm{K}^{-1}\right)$ at $120 \mathrm{GPa}$ and $2000 \mathrm{~K}$, and the $C_{P}$ of $\left[\mathrm{Fe}^{3+}-\mathrm{H}\right]_{\mathrm{Mg}-\mathrm{Mg}}-\mathrm{PPv}$ is almost near that of pure-PPv at lower mantle conditions (Figure 4c and Supplementary Materials Table S2). This tendency is the same as those of the Brg-phase. The isochoric heat capacity $C_{V}$ in all systems decreases with pressure when the temperature is lower than $2000 \mathrm{~K}$, but at the mantle, relevant temperatures $C_{V}$ become insensitive to pressure changing (Supplementary Materials Figures S9 and S10). Moreover, the $\left[\mathrm{Fe}^{3+}-\mathrm{H}\right]_{\mathrm{Si}}$ defect can yield a large isochoric heat capacity than the $\left[\mathrm{Fe}^{3+}-\mathrm{H}\right]_{\mathrm{Mg}-\mathrm{Mg}}$ defect and pure system whether in the Brg- or PPv-phase (Supplementary Materials Figures S9 and S10). The thermodynamic Grüneisen parameter $\gamma\left(\gamma=\alpha V K_{T} / C_{V}\right)$ of the Brg-phase and the PPv-phase are displayed in Figures $3 \mathrm{~d}$ and $4 \mathrm{~d}$ and Tables S1 and S2, respectively. The $\gamma$ of $\left[\mathrm{Fe}^{3+}-\mathrm{H}\right]_{\mathrm{Si}}-\mathrm{Brg}$ is larger than that of $\left[\mathrm{Fe}^{3+}-\mathrm{H}\right]_{\mathrm{Mg}-\mathrm{Mg}}-\mathrm{Brg}$ at all investigated pressures and temperatures, as shown in Figure 3d and Supplementary Materials Table S1. At pressures lower than 90 GPa, pure-Brg has a smaller or almost equal $\gamma$ compared to the hydrous $\mathrm{Fe}^{3+}$-bearing systems; however, when pressure is higher than $90 \mathrm{GPa}$, the $\gamma$ of pure-Brg becomes significantly higher than that of both $\left[\mathrm{Fe}^{3+}-\mathrm{H}\right]_{\mathrm{Si}}-\mathrm{Brg}$ and $\left[\mathrm{Fe}^{3+}-\mathrm{H}\right]_{\mathrm{Mg}-\mathrm{Mg}}-\mathrm{Brg}$, particularly at $150 \mathrm{GPa}$. The $\gamma$ of all systems is gradually increased when the temperature increases, and this effect of temperature is increasingly suppressed at high pressures. As for the PPv-phase, compared to pure-PPv, the incorporation of hydrogen and $\mathrm{Fe}^{3+}$ via the $\left[\mathrm{Fe}^{3+}-\mathrm{H}\right]_{\mathrm{Si}}$ defect increases the $\gamma$ of the PPv-phase significantly at pressures below $150 \mathrm{GPa}$, but these two values converge around $150 \mathrm{GPa}$ and $4000 \mathrm{~K}$. Unlike $\left[\mathrm{Fe}^{3+}-\mathrm{H}\right]_{\mathrm{Si}}-\mathrm{PPV}$, the presence of an $\left[\mathrm{Fe}^{3+}-\mathrm{H}\right]_{\mathrm{Mg}-\mathrm{Mg}}$ defect always decreases the $\gamma$ of the PPv-phase at all pressures and temperatures that we studied (Figure $4 \mathrm{~d}$ and Supplementary Materials Table S2). Furthermore, the $\gamma$ of $\left[\mathrm{Fe}^{3+}-\mathrm{H}\right]_{\mathrm{Mg}-\mathrm{Mg}}-$ $\mathrm{PPv}$ is also less than $\left[\mathrm{Fe}^{3+}-\mathrm{H}\right]_{\mathrm{Si}}-\mathrm{PPv}$ observable across the lower mantle range. We find that the effects of $\mathrm{H}$ and $\mathrm{Fe}^{3+}$ defect on the fundamental thermodynamic properties (such as $K_{T}$, $\left.\alpha, C_{P}\right)$ of $\mathrm{MgSiO}_{3}$ are moderate due to a low $\mathrm{H}$ and $\mathrm{Fe}^{3+}$ concentration in structure, but that the Grüneisen parameter $\gamma$ is sensitive to the presence of hydrogen and ferric atoms. The $\mathrm{Fe}^{3+}-\mathrm{H}$ defect will yield the change with up to $\sim 6.5 \%$ on the Grüneisen parameter. With a typical mantle concentration of $1000 \mathrm{wt}$. ppm this change is $\sim 1.2 \%$. This may imply that even a small amount of water may affect the anharmonicity of $\mathrm{Fe}^{3+}$-bearing $\mathrm{MgSiO}_{3}$ in lower mantle conditions. This will also affect the adiabaticity of the mantle in the presence of sufficient $\mathrm{Fe}$ and $\mathrm{H}$. The anharmonicity of the $\mathrm{MgSiO}_{3}$ system when water is presented needs further consideration.

The vibrational contribution to the entropy $S_{\text {vib }}$ as a function of temperature at different pressures is displayed in Supplementary Materials Figure S11 and Table S1 for the Brg-phase and Supplementary Materials Figure S12 and Table S2 for the PPv-phase. In Figures S11 and S12, we see that vibrational entropy of the system is increased with the temperature increase but decreased with pressure. This variation trend is consistent with the results of a previous study on the dry $\mathrm{MgSiO}_{3}$ or transition zone minerals $[27,28,59-61]$. In both $\mathrm{Brg}$ and $\mathrm{PPv}$-phase, $\left[\mathrm{Fe}^{3+}-\mathrm{H}\right]_{\mathrm{Si}}$ defect will produce a high vibrational entropy, whereas the vibrational entropy of the system is less affected by the incorporation of $\left[\mathrm{Fe}^{3+}-\mathrm{H}\right]_{\mathrm{Mg}-\mathrm{Mg}}$, further showing that $\left[\mathrm{Fe}^{3+}-\mathrm{H}\right]_{\mathrm{Si}}$ is the stable defect in these systems. The difference between $\left[\mathrm{Fe}^{3+}-\mathrm{H}\right]_{\mathrm{Si}}$ containing Brg and PPv is $\sim 2.1 \mathrm{~J} \mathrm{~mol}^{-1} \mathrm{~K}^{-1}$ at conditions close to the $\mathrm{D}^{\prime \prime}(127 \mathrm{GPa}$ and $2500 \mathrm{~K})$ and thus in the presence of Fe and $\mathrm{H}$ Brg is further favored by temperature than in PPv, which will serve to enhance the possibility of double-crossing though a full phase diagram needs to be constructed at this point.

Our entropy calculation indicates that, whether in bridgmanite or post-perovskite, the $\left[\mathrm{Fe}^{3+}-\mathrm{H}\right]_{\mathrm{Si}}$ configuration will produce a higher entropy than the $\left[\mathrm{Fe}^{3+}-\mathrm{H}\right]_{\mathrm{Mg}-\mathrm{Mg}}$ configuration at the P-T conditions of the lower mantle. This means that hydrous and ferric iron will more preferentially be substituted into the $\mathrm{Brg}$ and $\mathrm{PPv}$ via a $\left[\mathrm{Fe}^{3+}-\mathrm{H}\right]_{\mathrm{Si}}$ defect. Our previous study found that the $\left[\mathrm{Fe}^{3+}-\mathrm{H}\right]$ defect would shift the PPv phase transition boundary [42]. We can conclude in this study that, when hydrogen and ferric iron are 
presented in the deep lower mantle, the phase transition boundary between $\mathrm{Brg}$ and $\mathrm{PPv}$ will prefer to move to the shallower part of the lower mantle, and the ridge region of the $\mathrm{D}^{\prime \prime}$ layer might be rich in Hydrogen and iron.

Temperature distribution in the deep mantle is important for constraining the thermal structure of the lower mantle. Estimation of the temperature profile in the lower mantle can help us determine the temperature distribution in this region and further better understand the thermal structure of the lower mantle. It is generally accepted that the adiabatic temperature profile can represent the variation of temperature in the Earth's mantle, and the adiabatic temperature gradient is expressed as the equation $(d T / d P)_{S}=T \gamma / K_{S}$. By assuming the lower mantle is approximated as the pyrolite composition with a mixture of $\sim 80 \%$ bridgmanite with $\left[\mathrm{Fe}^{3+}-\mathrm{H}\right]_{\mathrm{Si}}$ and $\sim 20 \%(\mathrm{Mg}, \mathrm{Fe}) \mathrm{O}$, we estimated the average adiabatic temperature gradient in the lower mantle is $\sim 0.43 \mathrm{~K} / \mathrm{km}$, which is higher than the results determined in the dry lower mantle of $\sim 0.27-\sim 0.32 \mathrm{~K} / \mathrm{km}[57,62,63]$. We obtained the temperature at the pressure of $\sim 127 \mathrm{GPa}$, which corresponding to the top of the $\mathrm{D}^{\prime \prime}$ layer is $\sim 2640 \mathrm{~K}$, which is higher than the temperature of $\sim 2500 \mathrm{~K}$ proposed by the previous studies $[57,64]$. The presence of water will make the adiabatic temperature profile in the lower mantle steeper than that of the dry condition. Moreover, at the top of the D" layer, those regions where the dominant component is hydrous $\mathrm{Fe}^{3+}$-bearing bridgmanite might have a higher temperature than the ambient lower mantle.

\section{Conclusions}

In this paper, we have investigated the vibrational and thermodynamic properties of hydrous iron-bearing bridgmanite and post-perovskite with different $\left[\mathrm{Fe}^{3+}-\mathrm{H}\right]$ configurations. The phonon dispersion curves of different hydrous configurations were calculated using GGA+U and the density functional perturbation theory (DFPT) method. The thermodynamic properties were determined using quasi-harmonic approximation (QHA) calculations.

In hydrous iron-bearing $\mathrm{MgSiO}_{3}$ systems, ferric $\left(\mathrm{Fe}^{3+}\right)$ iron mainly affects the low phonon frequency parts of the system; however, the incorporation of hydrogen contributes to the highest phonon frequency parts. Water and iron incorporation will lead to vibrational instability of $\mathrm{MgSiO}_{3}$ at pressures lower than $30 \mathrm{GPa}$. Furthermore, the variation of phonon frequencies with pressure is strongly affected by the different site occupancy of $\mathrm{H}$ and $\mathrm{Fe}^{3+}$ in the lattice (i.e., in the Si site or $\mathrm{Mg}$ site).

The presence of ferric and hydrogen can affect the thermodynamic properties of the $\mathrm{MgSiO}_{3}$ system further. Of all the defect configurations that we considered, $\left[\mathrm{Fe}^{3+}-\mathrm{H}\right]_{\mathrm{Si}}$ defects produce the largest effect on the thermodynamic properties of Brg and PPv compared to $\left[\mathrm{Fe}^{3+}-\mathrm{H}\right]_{\mathrm{Mg}-\mathrm{Mg}}$ defects and the pure system. $\left[\mathrm{Fe}^{3+}-\mathrm{H}\right]_{\mathrm{Si}}$ defects increase the fundamental thermodynamic parameters, including isothermal bulk modulus $K_{T}$, thermal expansion coefficient $\alpha$, heat capacity $C_{P}, C_{V}$ and vibrational contribution to the entropy $S_{\text {vib }}$ for both Brg and PPv. The $\left[\mathrm{Fe}^{3+}-\mathrm{H}\right]_{\mathrm{Mg}-\mathrm{Mg}}$ defect, however, only makes slight changes to the above thermodynamic parameters. In addition, among the thermodynamic parameters we studied, the Grüneisen parameter $\gamma$ is the most sensitive to the incorporation of hydrogen and ferric iron but the variation trends of $\gamma$ with defect configuration, pressure and temperature is complex. Although we have studied the effects of water, defect configurations, temperature, and pressure on the vibrational and thermodynamic properties of bridgmanite and post-perovskite, the influence of concentration of water and iron still needs to be further studied.

Supplementary Materials: The following are available online at https:/ / www.mdpi.com/article/10 $.3390 / \mathrm{min} 11080885 / \mathrm{s} 1$, Figure S1: Crystal structures in details of $\left[\mathrm{Fe}^{3+}-\mathrm{H}\right]_{\mathrm{Si}}-\mathrm{Brg}$. In lattice structure, orange, dark blue, red, grey, and black spheres represent magnesium, silicon, oxygen, iron, and hydrogen, respectively. Figure S2: Crystal structures in details of $\left[\mathrm{Fe}^{3+}-\mathrm{H}\right]_{\mathrm{Si}}-\mathrm{PPv}$. In lattice structure, orange, dark blue, red, grey, and black spheres represent magnesium, silicon, oxygen, iron, and hydrogen, respectively. Figure S3: Crystal structures in details of $\left[\mathrm{Fe}^{3+}-\mathrm{H}\right]_{\mathrm{Mg}-\mathrm{Mg}}-\mathrm{Brg}$. In lattice structure, orange, dark blue, red, grey, and black spheres represent magnesium, silicon, oxygen, iron, 
and hydrogen, respectively. Figure S4: Crystal structures in details of $\left[\mathrm{Fe}^{3+}-\mathrm{H}\right]_{\mathrm{Mg}-\mathrm{Mg}}-\mathrm{PPv}$. In lattice structure, orange, dark blue, red, grey, and black spheres represent magnesium, silicon, oxygen, iron, and hydrogen, respectively. Figure S5: Phonon dispersion curves and vibrational density of states (VDoS) of $\left[\mathrm{Fe}^{3+}-\mathrm{H}\right]_{\mathrm{Si}}-\mathrm{Brg}$ with $\mathrm{HS} \mathrm{Fe}^{3+}$ at $60 \mathrm{GPa}(\mathrm{a})$ and $150 \mathrm{GPa}(\mathrm{b})$. $\mathrm{B}_{\mathrm{HS}}$ indicates that the high spin $\mathrm{Fe}^{3+}$ in the B site (Si site). Total VDoS and partial VDoS of Mg, Si, Fe (HS), H are shown by light blue, orange, green, red, and purple, respectively. Figure S6: Phonon dispersion curves and vibrational density of states (VDoS) of $\left[\mathrm{Fe}^{3+}-\mathrm{H}\right]_{\mathrm{Si}}-\mathrm{PPv}$ with $\mathrm{LS} \mathrm{Fe}^{3+}$ at $60 \mathrm{GPa}(\mathrm{a})$ and $150 \mathrm{GPa}(\mathrm{b})$. $\mathrm{B}_{\mathrm{LS}}$ indicates that the low spin $\mathrm{Fe}^{3+}$ in B site (Si site). Total VDoS and partial VDoS of Mg, Si, Fe (LS), $\mathrm{H}$ are shown by light blue, orange, green, red, and purple, respectively. Figure S7: Phonon dispersion curves and vibrational density of states (VDoS) of $\left[\mathrm{Fe}^{3+}-\mathrm{H}\right]_{\mathrm{Si}_{\mathrm{i}}}-\mathrm{PPv}$ with $\mathrm{HS} \mathrm{Fe}^{3+}$ at $60 \mathrm{GPa}(\mathrm{a})$ and $150 \mathrm{GPa}(\mathrm{b})$. $\mathrm{B}_{\mathrm{HS}}$ indicates that the high spin $\mathrm{Fe}^{3+}$ in the $\mathrm{B}$ site ( $\mathrm{Si}$ site). Total VDoS and partial VDoS of $\mathrm{Mg}, \mathrm{Si}$, $\mathrm{Fe}$ (HS), $\mathrm{H}$ are shown by light blue, orange, green, red, and purple, respectively. Figure S8: Phonon dispersion curves and vibrational density of states (VDoS) of $\left[\mathrm{Fe}^{3+}-\mathrm{H}\right]_{\mathrm{Mg}-\mathrm{Mg}}-\mathrm{PPv}$ at $60 \mathrm{GPa}(\mathrm{a})$ and $150 \mathrm{GPa}(\mathrm{b}) . \mathrm{A}_{\mathrm{HS}}$ indicates that the high spin $\mathrm{Fe}^{3+}$ in A site (Mg site). Total VDoS and partial VDoS of $\mathrm{Mg}, \mathrm{Si}, \mathrm{Fe}$ (HS), $\mathrm{H}$ are shown by light blue, orange, green, red, and purple, respectively. Figure S9: The heat capacity at constant volume as a function of temperature at different pressures. Solid, dashed, and dotted lines represent the $\left[\mathrm{Fe}^{3+}-\mathrm{H}\right]_{\mathrm{Si}^{-}}-\mathrm{Brg}$, $\left[\mathrm{Fe}^{3+}-\mathrm{H}\right]_{\mathrm{Mg}-\mathrm{Mg}}-\mathrm{Brg}$, and Pure- $\mathrm{Brg}$, respectively. Figure S10: The heat capacity at constant volume as a function of temperature at different pressures. Solid, dashed, and dotted lines represent the $\left[\mathrm{Fe}^{3+}-\mathrm{H}\right]_{\mathrm{Si}}-\mathrm{PPv},\left[\mathrm{Fe}^{3+}-\mathrm{H}\right]_{\mathrm{Mg}-\mathrm{Mg}}-\mathrm{PPv}$, and Pure-PPv, respectively. Figure S11: Temperature dependence of vibrational entropy at different pressures. Solid, dashed, and dotted lines represent the $\left[\mathrm{Fe}^{3+}-\mathrm{H}\right]_{\mathrm{Si}^{-}}-\mathrm{Brg}$, $\left[\mathrm{Fe}^{3+}-\mathrm{H}\right]_{\mathrm{Mg}-\mathrm{Mg}}-\mathrm{Brg}$, and Pure- $\mathrm{Brg}$, respectively. Figure S12: Temperature dependence of vibrational entropy at different pressures. Solid, dashed, and dotted lines represent the $\left[\mathrm{Fe}^{3+}-\mathrm{H}\right]_{\mathrm{Si}}-\mathrm{PPv},\left[\mathrm{Fe}^{3+}-\mathrm{H}\right]_{\mathrm{Mg}-\mathrm{Mg}}-\mathrm{PPv}$, and Pure-PPv, respectively. Table S1: Calculated thermodynamic parameters of hydrous iron-bearing and pure structure for bridgmanite. Table S2: Calculated thermodynamic parameters of hydrous iron-bearing and pure structure for post-perovskite.

Author Contributions: Conceptualization, F.Z.; methodology, J.J.; formal analysis, J.J. and J.M.R.M.; investigation, J.J.; data curation, J.J.; writing—original draft preparation, J.J.; writing-review and editing, F.Z. and J.M.R.M.; supervision, F.Z.; project administration, F.Z.; funding acquisition, F.Z. All authors have read and agreed to the published version of the manuscript.

Funding: This research was funded by the National Natural Science Foundation of China (grant number: 41773057 (01/2018-12/2021), 42050410319 (01/2021-12/2022)).

Data Availability Statement: The data that support the findings of this study are available from the corresponding author upon reasonable request.

Acknowledgments: The authors thank the computations support of the National Supercomputer Center in Shenzhen, China, and Supercomputer Center in Lvliang, China.

Conflicts of Interest: The authors declare no conflict of interest.

\section{References}

1. Irifune, T.; Tsuchiya, T. Mineralogy of the Earth-Phase transitions and mineralogy of the lower mantle. In Treatise on Geophysics; Schubert, G., Ed.; Elsevier: Amsterdam, The Netherlands, 2007; pp. 33-62.

2. Lin, J.F.; Speziale, S.; Mao, Z.; Marquardt, H. Effects of the electronic spin transitions of iron in lower mantle minerals: Implications for deep mantle geophysics and geochemistry. Rev. Geophys. 2013, 51, 244-275. [CrossRef]

3. Murakami, M.; Hirose, K.; Kawamura, K.; Sata, N.; Ohishi, Y. Post-perovskite phase transition in $\mathrm{MgSiO}_{3}$. Science 2004, 304, 855-858. [CrossRef]

4. Oganov, A.R.; Ono, S. Theoretical and experimental evidence for a post-perovskite phase of $\mathrm{MgSiO}_{3}$ in Earth's D" layer. Nature 2004, 430, 445-448. [CrossRef]

5. Tsuchiya, T.; Tsuchiya, J.; Umemoto, K.; Wentzcovitch, R.M. Phase transition in $\mathrm{MgSiO}_{3}$ perovskite in the earth's lower mantle. Earth Planet. Sci. Lett. 2004, 224, 241-248. [CrossRef]

6. Sun, N.; Wei, W.; Han, S.; Song, J.; Li, X.; Duan, Y.; Prakapenka, V.B.; Mao, Z. Phase transition and thermal equations of state of $(\mathrm{Fe}, \mathrm{Al})$-bridgmanite and post-perovskite: Implication for the chemical heterogeneity at the lowermost mantle. Earth Planet. Sci. Lett. 2018, 490, 161-169. [CrossRef]

7. Lay, T.; Garnero, E.J. Reconciling the Post-Perovskite Phase with Seismological Observations of Lowermost Mantle Structure; Washington DC American Geophysical Union Geophysical Monograph Series; American Geophysical Union: Malden, MA, USA, 2007; Volume 174, pp. 129-153. [CrossRef] 
8. Murakami, M.; Sinogeikin, S.V.; Bass, J.D.; Sata, N.; Ohishi, Y.; Hirose, K. Sound velocity of MgSiO 3 post-perovskite phase: A constraint on the D" discontinuity. Earth Planet. Sci. Lett. 2007, 259, 18-23. [CrossRef]

9. Dorfman, S.M.; Meng, Y.; Prakapenka, V.B.; Duffy, T.S. Effects of Fe-enrichment on the equation of state and stability of $(\mathrm{Mg}, \mathrm{Fe}) \mathrm{SiO}_{3}$ perovskite. Earth Planet. Sci. Lett. 2013, 361, 249-257. [CrossRef]

10. Grocholski, B.; Catalli, K.; Shim, S.H.; Prakapenka, V. Mineralogical effects on the detectability of the postperovskite boundary. Proc. Natl. Acad. Sci. USA 2012, 109, 2275-2279. [CrossRef] [PubMed]

11. Tateno, S.; Hirose, K.; Sata, N.; Ohishi, Y. Phase relations in $\mathrm{Mg}_{3} \mathrm{Al}_{2} \mathrm{Si}_{3} \mathrm{O}_{12}$ to $180 \mathrm{GPa}$ : Effect of Al on post-perovskite phase transition. Geophys. Res. Lett. 2005, 32, 1-4. [CrossRef]

12. Sinmyo, R.; McCammon, C.; Dubrovinsky, L. The spin state of $\mathrm{Fe}^{3+}$ in lower mantle bridgmanite. Am. Mineral. 2017, 102, 1263-1269. [CrossRef]

13. Frost, D.J.; Liebske, C.; Langenhorst, F.; McCammon, C.A.; Tronnes, R.G.; Rubie, D.C. Experimental evidence for the existence of iron-rich metal in the Earth's lower mantle. Nature 2004, 428, 409-412. [CrossRef]

14. Liu, Z.D.; McCammon, C.; Wang, B.; Dubrovinsky, L.; Ishii, T.; Bondar, D.; Nakajima, A.; Tange, Y.; Higo, Y.J.; Cui, T.; et al. Stabili and solubility of the $\mathrm{FeAlO}_{3}$ component in bridgmanite at uppermost lower mantle conditions. J. Geophys. Res. Solid Earth 2020, 125, 1-16. [CrossRef]

15. Frost, D.J.; McCammon, C.A. The redox state of Earth's mantle. Annu. Rev. Earth Planet. Sci. 2008, 36, 389-420. [CrossRef]

16. Catalli, K.; Shim, S.H.; Prakapenka, V.B.; Zhao, J.Y.; Sturhahn, W.; Chow, P.; Xiao, Y.M.; Liu, H.Z.; Cynn, H.; Evans, W.J. Spin state of ferric iron in $\mathrm{MgSiO}_{3}$ perovskite and its effect on elastic properties. Earth Planet. Sci. Lett. 2010, 289, 68-75. [CrossRef]

17. Hsu, H.; Yu, Y.G.G.; Wentzcovitch, R.M. Spin crossover of iron in aluminous $\mathrm{MgSiO}_{3}$ perovskite and post-perovskite. Earth Planet. Sci. Lett. 2012, 359, 34-39. [CrossRef]

18. Mao, Z.; Lin, J.F.; Yang, J.; Inoue, T.; Prakapenka, V.B. Effects of the $\mathrm{Fe}^{3+}$ spin transition on the equation of state of bridgmanite. Geophys. Res. Lett. 2015, 42, 4335-4342. [CrossRef]

19. Zhang, F.; Oganov, A.R. Valence state and spin transitions of iron in Earth's mantle silicates. Earth Planet. Sci. Lett. 2006, 249, 436-443. [CrossRef]

20. Fiquet, G.; Dewaele, A.; Andrault, D.; Kunz, M.; Le Bihan, T. Thermoelastic properties and crystal structure of MgSiO3 perovskite at lower mantle pressure and temperature conditions. Geophys. Res. Lett. 2000, 27, 21-24. [CrossRef]

21. Katsura, T.; Yokoshi, S.; Kawabe, K.; Shatskiy, A.; Manthilake, M.; Zhai, S.M.; Fukui, H.; Hegoda, H.; Yoshino, T.; Yamazaki, D.; et al. P-V-T relations of $\mathrm{MgSiO} 3$ perovskite determined by in situ X-ray diffraction using a large-volume high-pressure apparatus. Geophys. Res. Lett. 2009, 36, 6. [CrossRef]

22. Mosenfelder, J.L.; Asimow, P.D.; Frost, D.J.; Rubie, D.C.; Ahrens, T.J. The MgSiO3 system at high pressure: Thermodynamic properties of perovskite, postperovskite, and melt from global inversion of shock and static compression data. J. Geophys. Res. Solid Earth 2009, 114, 16. [CrossRef]

23. Karki, B.B.; Wentzcovitch, R.M.; de Gironcoli, S.; Baroni, S. First principles thermoelasticity of MgSiO3-perovskite: Consequences for the inferred properties of the lower mantle. Geophys. Res. Lett. 2001, 28, 2699-2702. [CrossRef]

24. Caracas, R.; Cohen, R.E. Effect of chemistry on the stability and elasticity of the perovskite and post-perovskite phases in the MgSiO3-FeSiO3-Al2O3 system and implications for the lowermost mantle. Geophys. Res. Lett. 2005, 32, 4. [CrossRef]

25. Tsuchiya, J.; Tsuchiya, T.; Wentzcovitch, R.M. Vibrational and thermodynamic properties of $\mathrm{MgSiO}_{3}$ postperovskite. J. Geophys. Res. Solid Earth 2005, 110, 1-6. [CrossRef]

26. Oganov, A.R.; Price, G.D. Ab initio thermodynamics of $\mathrm{MgSiO} 3$ perovskite at high pressures and temperatures. J. Chem. Phys. 2005, 122, 1-6. [CrossRef]

27. Metsue, A.; Tsuchiya, T. Lattice dynamics and thermodynamic properties of $\left(\mathrm{Mg}_{,} \mathrm{Fe}^{2+}\right) \mathrm{SiO}_{3}$ postperovskite. J. Geophys. Res. Solid Earth 2011, 116, 11. [CrossRef]

28. Metsue, A.; Tsuchiya, $\mathrm{T}$. Thermodynamic properties of $\left(\mathrm{Mg}, \mathrm{Fe}^{2+}\right) \mathrm{SiO}_{3}$ perovskite at the lower-mantle pressures and temperatures: An internally consistent LSDA+U study. Geophys. J. Int. 2012, 190, 310-322. [CrossRef]

29. Tsuchiya, T.; Wang, X.L. Ab initio investigation on the high-temperature thermodynamic properties of $\mathrm{Fe}^{3+}$-bearing $\mathrm{MgSiO}_{3}$ perovskite. J. Geophys. Res. Solid Earth 2013, 118, 83-91. [CrossRef]

30. Wang, X.L.; Tsuchiya, T.; Hase, A. Computational support for a pyrolitic lower mantle containing ferric iron. Nat. Geosci. 2015, 8 , 556-559. [CrossRef]

31. Gonnermann, H.M.; Mukhopadhyay, S. Non-equilibrium degassing and a primordial source for helium in ocean-island volcanism. Nature 2007, 449, 1037-1040. [CrossRef] [PubMed]

32. Hallis, L.J.; Huss, G.R.; Nagashima, K.; Taylor, G.J.; Halldorsson, S.A.; Hilion, D.R.; Mottl, M.J.; Meech, K.J. Evidence for primordial water in Earth's deep mantle. Science 2015, 350, 795-797. [CrossRef] [PubMed]

33. Inoue, T.; Wada, T.; Sasaki, R.; Yurimoto, H. Water partitioning in the Earth's mantle. Phys. Earth Planet. Inter. 2010, 183, $245-251$. [CrossRef]

34. Ohtani, E. Hydrous minerals and the storage of water in the deep mantle. Chem. Geol. 2015, 418, 6-15. [CrossRef]

35. Pearson, D.G.; Brenker, F.E.; Nestola, F.; McNeill, J.; Nasdala, L.; Hutchison, M.T.; Matveev, S.; Mather, K.; Silversmit, G.; Schmitz, S.; et al. Hydrous mantle transition zone indicated by ringwoodite included within diamond. Nature 2014, 507, 221-224. [CrossRef] [PubMed] 
36. Bolfan-Casanova, N.; Keppler, H.; Rubie, D.C. Water partitioning at $660 \mathrm{~km}$ depth and evidence for very low water solubility in magnesium silicate perovskite. Geophys. Res. Lett. 2003, 30, 1-4. [CrossRef]

37. Panero, W.R.; Pigott, J.S.; Reaman, D.M.; Kabbes, J.E.; Liu, Z.X. Dry (Mg,Fe)SiO 3 perovskite in the Earth's lower mantle. J. Geophys. Res. Solid Earth 2015, 120, 894-908. [CrossRef]

38. Litasov, K.; Ohtani, E.; Langenhorst, F.; Yurimoto, H.; Kubo, T.; Kondo, T. Water solubility in Mg-perovskites and water storage capacity in the lower mantle. Earth Planet. Sci. Lett. 2003, 211, 189-203. [CrossRef]

39. Murakami, M.; Hirose, K.; Yurimoto, H.; Nakashima, S.; Takafuji, N. Water in Earth's lower mantle. Science 2002, 295, 1885-1887. [CrossRef]

40. Fu, S.Y.; Yang, J.; Karato, S.; Vasiliev, A.; Presniakov, M.Y.; Gavriliuk, A.G.; Ivanova, A.G.; Hauri, E.H.; Okuchi, T.; Purevjav, $\mathrm{N}$; ; et al. Water concentration in single-crystal (Al,Fe)-bearing bridgmanite grown from the hydrous melt: Implications for dehydration melting at the topmost lower mantle. Geophys. Res. Lett. 2019, 46, 10346-10357. [CrossRef]

41. Townsend, J.P.; Tsuchiya, J.; Bina, C.R.; Jacobsen, S.D. Water partitioning between bridgmanite and postperovskite in the lowermost mantle. Earth Planet. Sci. Lett. 2016, 454, 20-27. [CrossRef]

42. Jiang, J.; Zhang, F. Theoretical studies on the hydrous lower mantle and D" layer minerals. Earth Planet. Sci. Lett. 2019, 525, 1-12. [CrossRef]

43. Kresse, G.; Furthmuller, J. Efficient iterative schemes for ab initio total-energy calculations using a plane-wave basis set. Phys. Rev. B 1996, 54, 11169-11186. [CrossRef] [PubMed]

44. Kresse, G.; Joubert, D. From ultrasoft pseudopotentials to the projector augmented-wave method. Phys. Rev. B 1999, 59, 1758-1775. [CrossRef]

45. Perdew, J.P.; Burke, K.; Ernzerhof, M. Generalized gradient approximation made simple. Phys. Rev. Lett. 1996, 77, 3865-3868. [CrossRef]

46. Hsu, H.; Blaha, P.; Cococcioni, M.; Wentzcovitch, R.M. Spin-state crossover and hyperfine interactions of ferric iron in $\mathrm{MgSiO}_{3}$ perovskite. Phys. Rev. Lett. 2011, 106, 1-4. [CrossRef]

47. Muir, J.M.R.; Brodholt, J.P. Ferric iron in bridgmanite and implications for ULVZs. Phys. Earth Planet. Inter. 2020, 306, 1-10. [CrossRef]

48. Monkhorst, H.J.; Pack, J.D. Special points for brillouin-zone integra tions. Phys. Rev. B 1976, 13, 5188-5192. [CrossRef]

49. Gonze, X.; Lee, C. Dynamical matrices, born effective charges, dielectric permittivity tensors, and interatomic force constants from density-functional perturbation theory. Phys. Rev. B 1997, 55, 10355-10368. [CrossRef]

50. Togo, A.; Chaput, L.; Tanaka, I.; Hug, G. First-principles phonon calculations of thermal expansion in $\mathrm{Ti}_{3} \mathrm{SiC}_{2}, \mathrm{Ti}_{3} \mathrm{AlC}_{2}$, and $\mathrm{Ti}_{3} \mathrm{GeC}_{2}$. Phys. Rev. B 2010, 81, 1-6. [CrossRef]

51. Yu, Y.G.G.; Hsu, H.; Cococcioni, M.; Wentzcovitch, R.M. Spin states and hyperfine interactions of iron incorporated in $\mathrm{MgSiO}_{3}$ post-perovskite. Earth Planet. Sci. Lett. 2012, 331, 1-7. [CrossRef]

52. Shukla, G.; Wentzcovitch, R.M. Spin crossover in $\left(\mathrm{Mg}, \mathrm{Fe}^{3+}\right)\left(\mathrm{Si}_{1} \mathrm{Fe}^{3+}\right) \mathrm{O}_{3}$ bridgmanite: Effects of disorder, iron concentration, and temperature. Phys. Earth Planet. Inter. 2016, 260, 53-61. [CrossRef]

53. Keppler, H.; Bolfan-Casanova, N. Thermodynamics of water solubility and partitioning. Rev. Mineral. Geochem. 2006, 62, 193-230. [CrossRef]

54. Wright, K. Atomistic models of $\mathrm{OH}$ defects in nominally anhydrous minerals. Rev. Mineral. Geochem. 2006, 62, 67-83. [CrossRef]

55. Smyth, J.R. Hydrogen in high pressure silicate and oxide mineral structures. Rev. Mineral. Geochem. 2006, 62, 1-85. [CrossRef]

56. Tsuchiya, T. First-principles prediction of the P-V-T equation of state of gold and the 660-km discontinuity in Earth's mantle. $J$. Geophys. Res. Solid Earth 2003, 108, 9. [CrossRef]

57. Akaogi, M.; Ito, E. Heat capacity of $\mathrm{MgSiO}_{3}$ perovskite. Geophys. Res. Lett. 1993, 20, 105-108. [CrossRef]

58. Akaogi, M.; Kojitani, H.; Morita, T.; Kawaji, H.; Atake, T. Low-temperature heat capacities, entropies and high-pressure phase relations of $\mathrm{MgSiO}_{3}$ ilmenite and perovskite. Phys. Chem. Miner. 2008, 35, 287-297. [CrossRef]

59. Yu, Y.G.G.; Wentzcovitch, R.M. Density functional study of vibrational and thermodynamic properties of ringwoodite. J. Geophys. Res. Solid Earth 2006, 111, 8. [CrossRef]

60. Yu, Y.G.G.; Wentzcovitch, R.M.; Vinograd, V.L.; Angel, R.J. Thermodynamic properties of $\mathrm{MgSiO}_{3}$ majorite and phase transitions near $660 \mathrm{~km}$ depth in $\mathrm{MgSiO}_{3}$ and $\mathrm{Mg}_{2} \mathrm{SiO}_{4}$ : A first principles study. J. Geophys. Res. Solid Earth 2011, 116, 1-19. [CrossRef]

61. Wu, Z.; Wentzcovitch, R.M. Vibrational and thermodynamic properties of wadsleyite: A density functional study. J. Geophys. Res. Solid Earth 2007, 112, 11. [CrossRef]

62. Brown, J.M.; Shankland, T.J. Thermodynamic parameters in the earth as determined from seismic profiles. Geophys. J. Royal Astron. Soc. 1981, 66, 579-596. [CrossRef]

63. Katsura, T.; Yoneda, A.; Yamazaki, D.; Yoshino, T.; Ito, E. Adiabatic temperature profile in the mantle. Phys. Earth Planet. Inter. 2010, 183, 212-218. [CrossRef]

64. Ono, S. Experimental constraints on the temperature profile in the lower mantle. Phys. Earth Planet. Inter. 2008, 170, 267-273. [CrossRef] 